\title{
Marketing management of tamarind in Karnataka
}

\author{
K. Shiny Israel and C. Murthy
}

Received : 01.08.2019; Revised : 13.09.2019; Accepted : 26.09.2019

\begin{abstract}
Tamarind (Tamarindus indica L.) grows especially in parts of sub-continent and it is a significant indigenous fruit tree. The origin of tamarind is from Eastern Africa in the place of Madagascar. But now it is grown in all over the world and extensively cultivated in India. For collection of primary data, the respondents were selected by random sampling method. The present paper reveals that the study area of Kolar, Bengulur, Tumkur and chikkaballapura were growing districts of tamarind in Karnataka. In Karnataka four processing units were selected and 25 farmers, 10 traders, 10 wholesalers, and 10 retailers were selected in each district. The producer's share of consumer rupee was found highest for channel -I at 81.49 per cent, followed by 71.02 and 68.00 per cent in channel -II and III, respectively. The price spread was for 2263.94 in channel-III followed by 1,915.62 in channel-II and 1,067.19 in channel-III, respectively. The wholesaler incurred marketing cost was due to processing, packaging and grading at Rs. 331.84 for channel -II followed by Rs. 330.09 in channel -III. The very low price of tamarind, lack of transport, storage and finance facilities followed by high level of exploitation by traders often discourages the gatherers interest for tamarind marketing. The price spread of tamarind was observed as high as 1,067 per quintal along with produces share in consumer's rupee was highest $(81 \%)$ in channel-I compared to all other three channels. Hence channel-I needs to be recommended and adopted for increased the increased profits in tamarind production. Tamarind growers expressed 82 per cent in the major problem of price fluctuation particularly ending with low price when compared with other problems like storage and commission. Hence government needs to initiate measures to protect the farmers from price fluctuations by way of giving minimum support price or taking measures for stabilized price.
\end{abstract}

KEY WORDS : Tamarind, Tamarind dried, Tamarind fresh, Tamarind seed, Marketing problems, Marketing channels, Processing unit problems

How to cite this paper : Israel, K. Shiny and Murthy, C. (2019). Marketing management of tamarind in Karnataka. Internat. J. Com. \& Bus. Manage, 12(2) : 77-84, DOI: 10.15740/HAS/IJCBM/12.2/77-84. Copyright@ 2019: Hind Agri-Horticultural Society.

MEMBERS OF THE RESEARCH FORUM

Correspondence to:

C. Murthy, Department of Agribusiness Management, College of Agriculture, University of Agricultural Sciences, Dharwad (Karnataka) India

E-mail: cmurthy1966@gmail.com

Authors' affiliations:

K. Shiny Israel, Department of Agribusiness Management, College of Agriculture, University of Agricultural Sciences, Dharwad (Karnataka) India

E-mail: Shiny_israel80@gmail.com 